\title{
Investigation on optimal spray properties for ground based agricultural applications using deposition and retention models
}

\author{
Nicolas De Cock ${ }^{\mathrm{a}, \mathrm{b}, *}$, Mathieu Massinon ${ }^{\mathrm{a}}$, Sofiene Ouled Taleb Salah ${ }^{\mathrm{a}, \mathrm{c}, \mathrm{d}}$, \\ Frédéric Lebeau $^{\mathrm{a}}$ \\ ${ }^{a}$ TERRA Teaching and Research Centre, Gembloux Agro-Bio Tech, University of Liege, \\ B-5030 Gembloux, Belgium \\ ${ }^{b}$ von Karman Institute for Fluid Dynamics, B-1640 Rhode-Saint-Genèse, Belgium \\ ${ }^{c}$ CESAM - GRASP, Institute of Physics, University of Liege, Building B5a, Sart Tilman, \\ B-4000 Liege, Belgium \\ ${ }^{d}$ TERRA - AgricultureIsLife, Gembloux Agro-Bio Tech, Passage des déportés 2, University \\ of Liege, B-5030 Gembloux, Belgium
}

\begin{abstract}
In crop protection, it is well know that droplet size determine spray efficacy. The optimisation of both spray deposition and retention leads to a dilemma: should small droplets be used to increase retention or large droplets be preferred to avoid drift? An ideal droplet should have a short time of flight to minimise its distance travelled while impacting the target with a moderate kinetic energy. This paper aims to determine an optimum range of droplet sizes for boom-sprayer applying herbicide using a modelling approach. The main parameters of spray deposition and retention models are systematically varied and the effects on drift potential and droplet impaction outcomes are discussed. The results of the numerical simulations showed that droplets with diameter ranging between $200 \mu \mathrm{m}$ and $250 \mu \mathrm{m}$ offer high control of deposition by combining a low drift potential and a moderate kinetic energy at top of the canopy. A fourfold reduction of the volume drifting further than $2 \mathrm{~m}$ from the nozzle was observed for a spray with a volume median diameter of $225 \mu \mathrm{m}$ when the relative span factor of the droplet spectrum was reduced from 1.0 to 0.6 . In the latter
\end{abstract}

\footnotetext{
* Corresponding author

Email address: nicolas.decock@ulg.ac.be (Nicolas De Cock)
} 
scenario, an increase from 63 to $67 \%$ of the volumetric proportion of droplets adhering to the wheat leaf was observed. Therefore, strategies for controlling the droplet size distribution may offer promising solutions for reducing adverse impact of spray applications on environment.

Keywords: stochastic Lagrangian; agricultural spray; droplet size distribution; drift; retention; relative span factor; deposition; retention;

\section{Introduction}

Spray application is a key process in crop protection to ensure high yields whilst minimising the adverse environmental and health impact of plant protection products. During this process, the agricultural mixture is usually atomised by passage through a nozzle generating a liquid sheet that further breaks up in a cloud of droplets. A herbicide application can be divided in four successive stages: deposition (initial spray amount minus off-target losses), retention (amount remaining on the plant after impaction), uptake (amount of active ingredient taken into the plant foliage) and translocation (amount of absorbed material translocated) (Zabkiewicz, 2007). This paper focuses on deposition and retention stages.

It has been shown that the droplet size distribution of the spray significantly affects the deposition (Hilz \& Vermeer, 2013, Nuyttens, De Schampheleire, Baetens \& Sonck, 2007b, Stainier, Destain, Schiffers \& Lebeau, 2006, Taylor, Womac, Miller \& Taylor, 2004), Al Heidary, Douzals, Sinfort \& Vallet (2014) showed that spray drift decreases with the droplet kinetic energy following a power law. Indeed, finer droplets are more prone to drift leading to potential product losses in the air, water and soil Reichenberger, Bach, Skitschak \& Frede, 2007). Modelling of deposition under field conditions has been realized using several approaches: Gaussian plume model Baetens, Ho, Nuyttens, De Schampheleire, Melese Endalew, Hertog, Nicolai, Ramon \& Verboven, 2009 Lebeau, Verstraete, Stainier \& Destain, 2011, Raupach, Briggs, Ford, Leys, 


\begin{tabular}{|c|c|c|c|}
\hline \multicolumn{4}{|c|}{ Nomenclature } \\
\hline \multicolumn{3}{|c|}{ Greek Symbols } & eled distance $[\mathrm{m}]$ \\
\hline$\beta$ & Droplet release angle $\left[^{\circ}\right]$ & $g$ & Gravity acceleration $\left[\mathrm{m} \mathrm{s}^{-2}\right]$ \\
\hline$\Delta t$ & Time step $[\mathrm{s}]$ & $h_{c}$ & Crop height $[\mathrm{m}]$ \\
\hline$\eta, \epsilon$ & Random value from a standard & $h_{r}$ & Release height [m] \\
\hline & normal distribution $[-]$ & $k$ & Liquid to gas dynamic viscosity \\
\hline$\gamma$ & Surface tension $\left[\mathrm{Nm}^{-1}\right]$ & & ratio $[-]$ \\
\hline$\kappa$ & von Karman constant [-] & $L$ & Monin-Obukhov length [m] \\
\hline$\lambda, K$ & Weibull distribution parameter [-] & $m$ & Droplet mass $[\mathrm{kg}]$ \\
\hline$\mu$ & Dynamic viscosity $\left[\mathrm{N} \mathrm{s} \mathrm{m}^{-2}\right]$ & $R e$ & Reynolds number [-] \\
\hline$\nu$ & Kinematic viscosity $\left[\mathrm{m} \mathrm{s}^{-2}\right]$ & $R S F$ & Relative span factor [-] \\
\hline$\rho$ & Volumetric mass $\left[\mathrm{kg} \mathrm{m}^{-3}\right]$ & ToF & Time of flight $[\mathrm{s}]$ \\
\hline$\sigma_{x, z}$ & Velocity RMS $\left[\mathrm{m} \mathrm{s}^{-1}\right]$ & $U$ & Air flow velocity $\left[\mathrm{m} \mathrm{s}^{-1}\right]$ \\
\hline$\tau_{L}$ & $\begin{array}{l}\text { Lagrangian time scale of turbu- } \\
\text { lence }[\mathrm{s}]\end{array}$ & $u$ & Droplet velocity $\left[\mathrm{m} \mathrm{s}^{-1}\right]$ \\
\hline$\tau_{L}^{*}$ & Modified Lagrangian timescale [s] & $U^{*}$ & Friction velocity $\left[\mathrm{m} \mathrm{s}^{-1}\right]$ \\
\hline$\theta$ & Static contact angle $\left[^{\circ}\right]$ & $u_{0}$ & Release velocity $\left[\mathrm{m} \mathrm{s}^{-1}\right]$ \\
\hline Roman & Symbols & $V_{r}$ & Relative droplet velocity $\left[\mathrm{m} \mathrm{s}^{-1}\right]$ \\
\hline$\dot{m}$ & Mass flux $\left[\mathrm{kg} \mathrm{s}^{-1}\right]$ & $W e$ & Weber number [-] \\
\hline$C_{D}$ & Drag coefficient [-] & $x$ & Horizontal position $[\mathrm{m}]$ \\
\hline$C D F$ & Cumulative density function [-] & $z$ & Vertical position [m] \\
\hline$d$ & Droplet diameter $[\mathrm{m}]$ & $z_{0}$ & Surface roughness $[\mathrm{m}]$ \\
\hline$d_{0}$ & Zero plane displacement [m] & Subsc & ipts \\
\hline$d_{m}$ & Maximum spread diameter [m] & $\mathrm{g}$ & Gaseous \\
\hline$E$ & Arithmetic mean of droplet trav- & 1 & Liquid \\
\hline
\end{tabular}

23 Muschal, Cooper \& Edge, 2001), Lagrangian models (Butler Ellis \& Miller,

24 2010; Holterman, Van De Zande, Porskamp \& Huijsmans, 1997; Mokeba, Salt,

25 Lee \& Ford, 1997; Teske, Bird, Esterly, Curbishley, Ray \& Perry, 2002; Walk-

26 late, 1987), computational fluid dynamics (CFD) (Baetens, Nuyttens, Verboven,

27 De Schampheleire, Nicolai \& Ramon, 2007, Weiner \& Parkin, 1993). Here a La-

28 grangian stochastic model will be used. Lagrangian stochastic models compute 
the droplet movement through an airflow using discrete time steps. The airflow turbulence is taken into account by superposing a time correlated fluctuating component onto a mean component. Dispersal statistics can be retrieved by tracking a large number of droplets.

The amount of spray remaining on a plant after impact is determined by the sum of each droplet impact outcomes (adhesion, bounce or shatter). Droplet behaviour after impact is mainly governed by droplet kinetic energy, liquid surface tension and the surface wetability (Josserand \& Thoroddsen, 2016, Yarin, 2006). When a droplet hits a solid surface, it spreads radially producing a thin liquid layer. If the droplet kinetic energy at impact overcomes capillary forces, the droplet shatters in smaller droplets. Otherwise, the spreading driven by the initial kinetic energy of the droplet is decelerated by viscous forces and surface tension, until radial dispersion stops. Thereafter, the liquid layer can remain pinned on the surface or retract. If the droplet surface energy is sufficient, the droplet may detach itself from the surface leading to a bounce Attané, Girard \& Morin, 2007). Otherwise, the droplet adheres on the surface. Massinon, Dumont, De Cock, Salah \& Lebeau (2015) proposed an empirical probabilistic model using droplet Weber number to model droplet outcomes on plant leaves. Deterministic models of impact outcomes based on energy balance of the impacting droplet are also available (Mao, Kuhn \& Tran, 1997, Mundo, Sommerfeld \& Tropea, 1995; Dorr, Wang, Mayo, McCue, Forster, Hanan \& He, 2015).

One common approach to reduce drift is to shift the droplet spectrum towards coarser droplets using low-drift nozzle or by adding spray additives. However, coarse droplets present a relatively low degree of surface coverage and may pounce or shatter on the target Hilz \& Vermeer, 2013, Massinon, De Cock, Forster, Nairn, McCue, Zabkiewicz \& Lebeau, 2017). An other solution, is to narrow the droplet size distribution towards an intermediate range of droplet size.

The goal of the present paper is to determine an optimum range of droplet size for boom-sprayer based herbicide applications using a modelling approach. A deposition model based on a stochastic Lagrangian approach is presented in 
the section 2.1. The mathematical models determining the droplet outcomes at canopy level are presented in the section 2.2. Deposition and retention models are used to realise a sensitivity analysis on initial droplet parameters (diameter, release height, release velocity) and environmental characteristics (wind speed, relative humidity) in the agricultural range detailed in section 2.4.1. Finally, the aerial transport and the retention of sprays with different volumetric median diameter and relative span factor are assessed in section 2.4 .2

\section{Materials and methods}

\subsection{Droplet deposition model}

\subsubsection{General overview of the droplet transport model}

Figure 1 shows the flow chart of the model. The simulation starts by initialising the droplet characteristics, e.g. its initial location, velocity and size. The acceleration and the evaporation of the droplet is then computed at each time step. In order to solve the aerodynamic balance of the droplet, the air flow characteristics are computed as well at each droplet location taking into account atmospheric turbulence. The simulation ends when the droplet either looses all its mass or reaches the crop level canopy where the droplet is stated to be captured. Air entrainment from the spray nozzle is not taken in account in the present model because of a low drop/air mass ratio is assumued which is typical of low application volume/high speed applications (Lebeau, 2004).

\subsubsection{Droplet motion}

口 Equations of droplet motion are taken from the saltation model of Kok

\& Renno (2009), which takes into account the particle inertia. The droplet transport model uses a Lagrangian description of the droplet motion. The displacement of the droplet after a time $t$ is given by the numerical integration of the droplet velocity over time:

$$
\Delta x_{i}=\sum_{i}^{n} u_{x, i} \Delta t_{i} \quad \& \quad \Delta z_{i}=\sum_{i}^{n} u_{z, i} \Delta t_{i}
$$




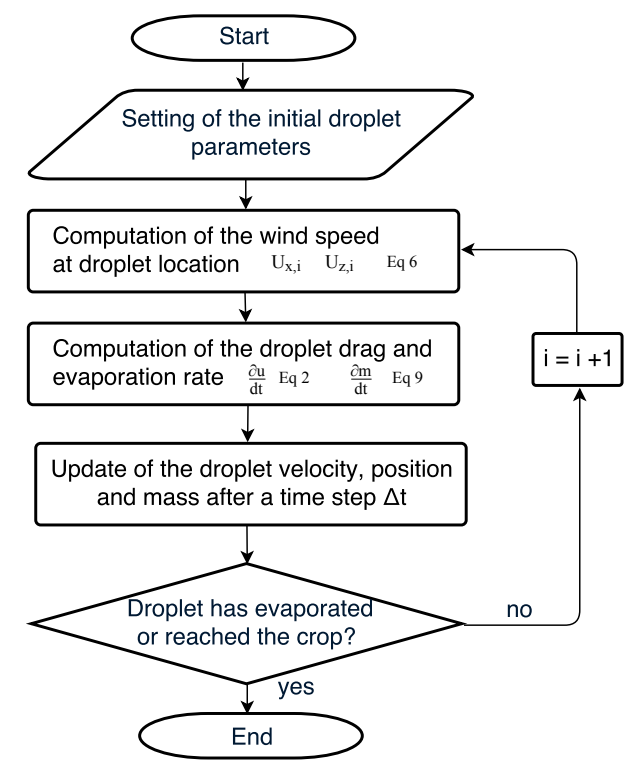

Fig. 1: Flow chart of the droplet transport model.

86 The variation of the droplet velocity is retrieved using Newton's second law of 87 motion taking in account the effects of drag and gravity while neglecting the buoyancy.

$$
\begin{gathered}
\frac{\partial u_{x}}{d t}=\frac{3 C_{D} \rho_{g} V_{r}\left(U_{x}-u_{x}\right)}{4 \rho_{l} d} \\
\frac{\partial u_{z}}{d t}=\frac{3 C_{D} \rho_{g} V_{r}\left(U_{z}-u_{z}\right)}{4 \rho_{l} d}-g
\end{gathered}
$$

89 with $m$ the droplet mass $[\mathrm{kg}], u$ the droplet velocity $\left[\mathrm{m} \mathrm{s}^{-1}\right], t$ the time $[\mathrm{s}], C_{D}$

90 the drag coefficient [-], $\rho_{l}$ and $\rho_{g}$ the density of the liquid and gaseous phases

${ }_{91}$ respectively $\left[\mathrm{kg} \mathrm{m}^{-3}\right], A$ the droplet cross section area $\left[\mathrm{m}^{2}\right], d$ the droplet diam-

92 eter $[m], U$ and $u$ are the air and the droplet velocity respectively $\left[\mathrm{m} \mathrm{s}^{-1}\right], V_{r}$ is

93 the relative velocity between the droplet and the airflow defined as $V_{r}=|u-U|$

${ }_{94}\left[\mathrm{~m} \mathrm{~s}^{-1}\right]$, and $g$ is the gravitational acceleration rounded to $9.81\left[\mathrm{~m} \mathrm{~s}^{-2}\right]$.

${ }_{95}$ For $R e \leq 400$ the drag coefficient of a sphere in a gas flow can be expressed 96 using the following expression (Saboni, Alexandrova \& Gourdon, 2004):

$$
C_{d}=\frac{\left(k\left(\frac{24}{R e}+\frac{4}{R e^{0.36}}\right)+\frac{15}{R e^{0.82}}-0.02 \frac{k R e^{0.5}}{1+k}\right) R e^{2}+40 \frac{3 k+2}{R e}+15 k+10}{(1+k)\left(5+0.95 R e^{2}\right)}
$$


with $k$ equal to the ratio of the liquid to the gas viscosity, $k=\frac{\mu_{l}}{\mu_{g}}$, and $R e$ the droplet Reynolds number defined as: $R e=\frac{V_{r} d}{\nu_{g}}$. Other $C_{d}$ expressions for a sphere can be found in the literature (Barati, Neyshabouri \& Ahmadi, 2014, Langmuir \& Blodgett, 1949).

\subsubsection{Description of the air flow}

The velocity profile generated by a wind above crop is made up of a random part sum onto a mean component. Assuming the vertical mean flow equal to zero, the general formulation is reduced to:

$$
U_{x}=\overline{U_{x}}+U_{x}^{\prime} ; \quad U_{z}=U_{z}^{\prime}
$$

The average part of the horizontal velocity $\bar{U}\left(z_{i}\right)$ is described by a logarithmic velocity profile:

$$
\bar{U}\left(z_{i}\right)=\frac{U^{*}}{\kappa} \log \left(\frac{z-d_{0}}{z_{0}}\right)
$$

with $\kappa$ the von Karman constant equals to $0.41[-], U^{*}$ the friction velocity $\left[\mathrm{ms}^{-} 1\right], z$ the distance above the ground $[\mathrm{m}], d_{0}$ the zero plane displacement $[\mathrm{m}]$ and $z_{0}$ the surface roughness $[\mathrm{m}]$. The values $d_{0}$ and $z_{0}$ can be related to crop height using $z_{0}=0.1 h_{c}$ and $d_{0}=0.63 h_{c}$ with $h_{c}$ the crop height (Butler Ellis \& Miller, 2010).

For homogeneous isotropic turbulence, the velocity fluctuations $U^{\prime}$ of an air particle moving with the flow can be statically described by the following set of equations (Kok \& Renno, 2009) (Wilson \& Sawford, 1996):

$$
\begin{aligned}
& U_{x, i+1}^{\prime}=U_{x, i}^{\prime} e^{-\frac{\Delta t}{\tau_{L x}^{*}}}+\epsilon \sigma_{x} \sqrt{2}\left(1-e^{\left(-\sqrt{\frac{\Delta t}{\tau_{L x}^{*}}}\right)}\right) \\
& U_{z, i+1}^{\prime}=U_{z, i}^{\prime} e^{-\frac{\Delta t}{\tau_{L z}^{*}}}+\eta \sigma_{z} \sqrt{2}\left(1-e^{\left(-\sqrt{\frac{\Delta t}{\tau_{L z}^{*}}}\right)}\right)
\end{aligned}
$$

15

$16 \epsilon$

117

with $\tau_{L}^{*}$ the modified Lagrangian time scale $[\mathrm{s}], \Delta t$ is the time step $[\mathrm{s}], \eta$ and $\epsilon$ are random variables from a standard normal distribution [-], $\sigma_{x}$ and $\sigma_{z}$ are the horizontal and the vertical velocity fluctuations $\left[\mathrm{ms}^{-} 1\right]$. For near neutral 
atmospheric conditions: $\sigma_{x}=2.3 U^{*}$ and $\sigma_{z}=1.3 U^{*}$ (Panofsky, Tennekes, Lenschow \& Wyngaard, 1977).

The Lagrangian timescale represents the approximate timescale over which the velocities experienced by an air particle are statically related. Since the droplets move through the air eddies, the Lagrangian timescale perceived by the droplets is shorter. A modified formulation of the Lagrangian timescale for the horizontal and the vertical directions was proposed by (Sawford \& Guest) 1991):

$$
\begin{aligned}
\tau_{L x}^{*} & =\frac{\tau_{L x}}{\sqrt{1+\left(2 \frac{V_{r}}{\sigma_{x}}\right)^{2}}} \\
\tau_{L z}^{*} & =\frac{\tau_{L z}}{\sqrt{1+\left(\frac{V_{r}}{\sigma_{z}}\right)^{2}}}
\end{aligned}
$$

with $\tau_{L}$ defined as (Butler Ellis \& Miller, 2010):

$$
\tau_{L}=\kappa U^{*} \frac{\left(z-d_{0}\right)}{\sigma_{z}^{2}} \sqrt{1-\left(\frac{16\left(z-d_{0}\right)}{L}\right)}
$$

with $L$ the Monin-Obukhov length [m], which characterises atmospheric stability.

\subsubsection{Droplet evaporation}

Droplet evaporation in the model was based on Guella, Alexandrova \& Saboni (2008). The set of equations used are described in the Appendix A. In this model, the air has a constant vapour fraction and temperature. The loss of droplet volume is computed after each time step as:

$$
\Delta m=\frac{\dot{m}}{\rho_{l}} \Delta t
$$

\subsection{Droplet retention model}

Mathematical models have been developed to predict the outcome of impacting droplets based on an energy balance approach(Dorr et al. 2015; Mao et al. 
1997 Mundo et al. 1995). In these models, three impact outcomes are considered: adhesion, bounce or shatter. Shatter occurs when the inertial forces at impacting overcome the capillary forces. The droplet shatter threshold may be predicted based on droplet Reynolds number and Weber number Mundo et al. (1995):

$$
K=W e^{0.5} R e_{I}^{0.25}
$$

Unlike for the drag coefficient, the Reynolds number of the droplet at impaction $R e_{I}$ is computed using the liquid kinematic viscosity: $R e_{I}=\frac{u_{z} d}{\nu_{l}}$. The Weber number is expressed as: $W e=\frac{u_{z}^{2} \rho_{l} d}{\gamma}$ with $\gamma$ the liquid tension surface $\left[\mathrm{Nm}^{-1}\right]$. Experimental measurements have shown that the droplets shatter when $W e^{0.5} \operatorname{Re}_{I}^{0.25} \geq K_{\text {crit }}$ (Mundo et al., 1995). If the droplet does not shatter, the model assesses the bounce criteria. Mao et al. (1997) proposed a semi-empirical model based on energy conservation providing a rebound criteria. Bounce occurs if the excess rebound energy $E_{E R E}^{*}$ is positive otherwise the droplet is predicted to adhere to the leaf. The excess rebound energy is defined as:

$$
E_{E R E}^{*}=\frac{1}{4}\left(\frac{d_{m}}{d}\right)^{2}(1-\cos \theta)+\frac{2}{3}\left(\frac{d}{d_{m}}\right)-0.12\left(\frac{d_{m}}{d}\right)^{2.3}(1-\cos \theta)^{0.63}-1
$$

with $d_{m}$ the maximum spread diameter $[\mathrm{m}]$ and $\theta$ the static contact angle $\left[^{\circ}\right]$.

The value of $d_{m}$ in the Eq.11 was, in turn, derived as an implicit function of $W e, R e$ and $\theta$ :

$$
\left[0.25(1-\cos \theta)+0.2 \frac{W e^{0.83}}{R e_{I}^{0.33}}\right]\left(\frac{d_{m}}{d}\right)^{3}-\left(\frac{W e}{12}+1\right)\left(\frac{d_{m}}{d}\right)+\frac{2}{3}=0
$$

If there is no real solution for $d_{m}$ in the Eq. 12 or if the computed $d_{m}$ is $\leq d$, the value of $d_{m}$ is set as equal to $d$.

\subsection{Numerical procedure}

Figure 2 illustrates the initial state of the simulation. The initial droplet location is set as $x=0$ and $z=h_{r}+h_{c}$ with $z_{r}$ the release droplet height $[\mathrm{m}]$. The initial droplet velocity in both directions are: $u_{x}=\left\|u_{0}\right\| \cos (\beta) ; u_{z}=$ $\left\|u_{0}\right\| \sin (\beta)$, with $\beta$ the angle between the initial droplet direction and the 


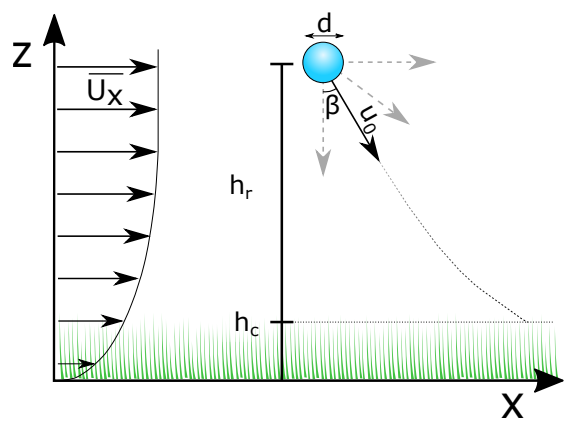

Fig. 2: Initial configuration of the deposition model.

Table 1: Simulation constants. The air and water temperature properties were taken both for $15^{\circ} \mathrm{C}$. Subscript $g$ and $l$ refer to gaseous and liquid phases respectively.

\begin{tabular}{c||c||c} 
Parameter & Value & Units \\
\hline \hline$\mu_{g}$ & $1.85 \mathrm{e}-5$ & $\mathrm{Pas}$ \\
$\mu_{l}$ & $1.15 \mathrm{e}-3$ & $\mathrm{Pas}$ \\
$\rho_{g}$ & 1.2 & $\mathrm{~kg} \mathrm{~m}^{-3}$ \\
$\rho_{l}$ & 1000 & $\mathrm{~kg} \mathrm{~m}^{-3}$ \\
$h_{c}$ & 0.1 & $\mathrm{~m}$ \\
$L$ & -1000 & $\mathrm{~m}$
\end{tabular}

vertical direction $\left[^{\circ}\right]$ and $u_{0}$ the release velocity $\left[\mathrm{m} \mathrm{s}^{-1}\right]$. Liquid and air properties used for the computations are shown in the Table1. The time step $\Delta t$ was computed as: $\min \left(\frac{0.1 h}{V_{r}}, \frac{\tau_{L}}{10}\right)[\mathrm{s}]$.

\subsection{Parameter sensitivity study}

\subsubsection{Monosized droplets}

A sensitivity analysis was performed to highlight the effect of the droplet diameter $d$, wind speed at a height of $2 \mathrm{~m} \bar{U}(2)$, droplet release velocity $u_{0}$, release angle $\beta$, the release height above crop $h_{r}$ and relative humidity $H r$ may have on the deposition and retention steps. The variation of these parameters are shown in the Table2. For each instance, the trajectories of 15000 droplets with the same initial conditions were computed. Random wind fluctuations experi- 
Table 2: Range of variation of the simulation parameters. The standard values are highlighted in bold.

\begin{tabular}{c||c||c} 
Variable & Tested values & Units \\
\hline \hline$d$ & $100 ; 125 ; 150 ; 175 ; 200 ; 250 ; 300 ; 350 ; 400$ & $\mu m$ \\
$\bar{U}(2)$ & $0 ; \mathbf{2} ; 4 ; 6 ; 8$ & $\mathrm{~m} \mathrm{~s}^{-1}$ \\
$\left\|u_{0}\right\|$ & $5 ; \mathbf{1 0} ; 15$ & $\mathrm{~m} \mathrm{~s}^{-1}$ \\
$\beta$ & $\mathbf{0} ; 15 ; 30 ; 45 ; 60 ; 75 ; 90$ & $\circ$ \\
$h_{r}$ & $0.25 ; \mathbf{0 . 5} ; 0.75 ; 1$ & $\mathrm{~m}$ \\
$H r$ & $40 ; 60 ; \mathbf{8 0}$ & $\%$
\end{tabular}

enced by the droplets during their flights lead to a variety of trajectories that were characterised by statistical parameters such as mean, $5^{\text {th }}, 50^{\text {th }}$ (median) and $95^{\text {th }}$ percentiles. Later in the paper, if the value of one parameter is not specified, the standard values indicated in bold in Table 2 were used.

The impact outcomes were evaluated on a wheat leaf with water which has a static contact angle of $132^{\circ}$ and a $K_{\text {crit }}$ of 69 (Forster, Mercer \& Schou, 2010). Water has a surface tension $\gamma$ of $0.072 \mathrm{~N} \mathrm{~m}^{-1}$.

\subsubsection{Polydisperse sprays}

The aerial transport of polydisperse sprays of droplets are simulated in order to predict the effect of the droplet size distribution on the overall deposition and retention. Each spray cloud was simulated by 100000 droplets randomly drawn from a Weibull distribution in volumetric cumulative distribution (CDF) defined as: $C D F=1-e^{-\left(\frac{-x}{\lambda}\right)^{K}}$ (Rosin \& Rammler, 1933, Babinsky \& Sojka, 2002).

The two Weibull distribution parameters were set to achieve a specific relative span factor $R S F$ and volumetric mean diameter $D v_{50}$. The relative span factor is defined as $R S F=\frac{D v_{90}-D v 10}{D v_{50}}$ with $D v_{10}, D v_{50}$ and $D v_{90}$ corresponding to the maximum droplet diameter below which $10 \%, 50 \%$ and $90 \%$ of the volume of the sample exists, respectively. Six different values of $D v_{50}(150,200,225,250$, $300,350 \mu \mathrm{m})$ and two $\operatorname{RSF}(0.6,1)$ were simulated resulting in twelve different simulations. The twelve simulated droplet size distributions are shown in Fig 3 


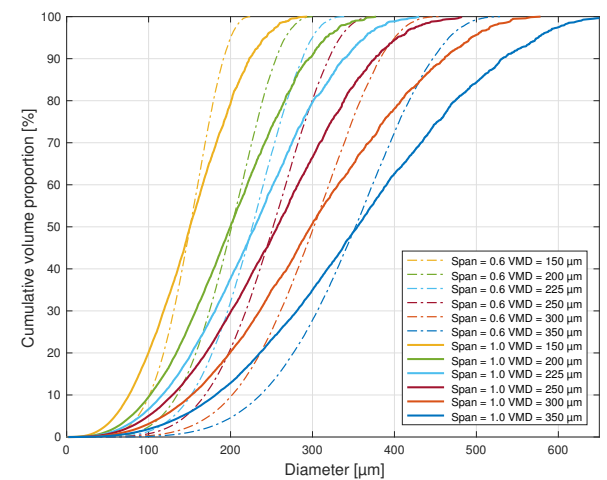

Fig. 3: Cumulative droplet size distribution of the virtual sprays for the six $D v_{50}$ and the two $R S F$.

Sprays characterised with a $R S F$ of 0.6 and 1 are representative of the narrow spray droplet size distributions produced by rotary atomisers (Qi, Miller \& $\mathrm{Fu}, 2008$ ) and flat fan nozzles respectively (De Cock, Massinon, Nuyttens, Dekeyser \& Lebeau, 2016; Nuyttens, Baetens, De Schampheleire \& Sonck, 2007a). A $D v_{50}$ of $250 \mu \mathrm{m}$ with a $R S F$ of 1 is similar to a spray generated by a flat fan nozzle 110-03 operating at at $300 \mathrm{kPa}$. For all these cases, simulation parameters were set to standard values (Table2).

\section{Results}

\subsection{Sensitivity analysis of a population of monodisperse droplets}

\subsubsection{Effect of droplet size on velocity dynamics}

Figure 4 a shows the evolution of the vertical median droplet velocity with respect to the droplet vertical position. The droplets are released $0.6 \mathrm{~m}$ above a crop of $0.1 \mathrm{~m}$ high with an initial horizontal velocity $u_{x}$ of $0 \mathrm{~m} \mathrm{~s}^{-1}$ and an initial vertical velocity $u_{z}$ of $-10 \mathrm{~m} \mathrm{~s}^{-1}$. The droplets were decelerating in the vertical direction approaching their settling velocity whilst, in the horizontal direction, the droplets were accelerating towards the wind velocity. The droplets with a diameter $\geq 250 \mu \mathrm{m}$ reached the crop canopy with a vertical velocity above their settling velocity. The median time of flight ( $\mathrm{ToF}$ ) for each droplet size is shown 
a)

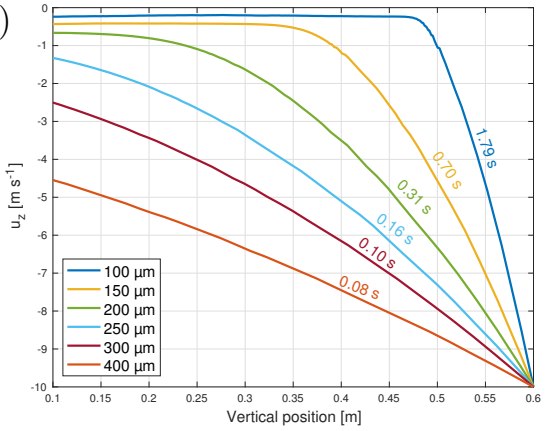

b)

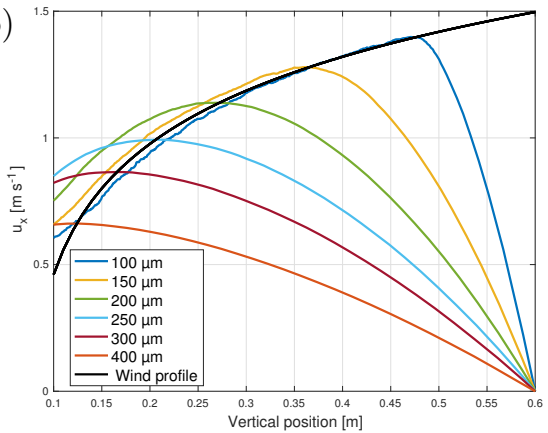

Fig. 4: a) Median vertical velocity with respect to the droplet vertical location. The median time of flight to travel from the release point to the crop top canopy for each droplet size is indicated above each corresponding line. b) Median horizontal velocity with respect to the droplet vertical location. The average wind velocity profile defined by the Eq 5 for a reference wind of $2 \mathrm{~ms}^{-1}$ at $2 \mathrm{~m}$ is illustrated by the black curve.

next to each line. The $\mathrm{ToF}$ is the time between the droplet release and its deposit on the canopy. Droplet ToF is shown decreasing with increasing droplet size. The $100 \mu m$ diameter droplets had, on average, 20 times longer ToF than $400 \mu \mathrm{m}$ diameter droplets. The ToF ratio between the $250 \mu \mathrm{m}$ and the $400 \mu \mathrm{m}$ diameter droplets was around 2.

Figure $4 \mathrm{~b}$ shows the evolution of the horizontal median droplet velocity with respect to the droplet vertical position. All droplet sizes reached the top canopy level at a horizontal velocity approximately equal to the average wind velocity. An overshoot of the wind velocity was observed for larger droplets due to their inertia, e.g. $250 \mu \mathrm{m}$ droplets are faster than the wind at $\mathrm{z} \leq 0.2 \mathrm{~m}$.

\subsubsection{Droplet trajectories}

The random wind fluctuations experienced by the droplets lead to a variability of trajectories among the simulations. Figure 5 a shows the $5^{\text {th }}, 50^{\text {th }}$ (median) and $95^{t h}$ percentile of the trajectories of 15000 droplets under reference conditions (cf Table 2). The median is represented by the solid line. The $5^{\text {th }}$ and $95^{\text {th }}$ percentile are represented by the left and the right dashed line respectively. The coarser the droplet, the shorter the horizontal distance travelled and the dispersion of the travelled distance. The droplets with diameter larger 
a)

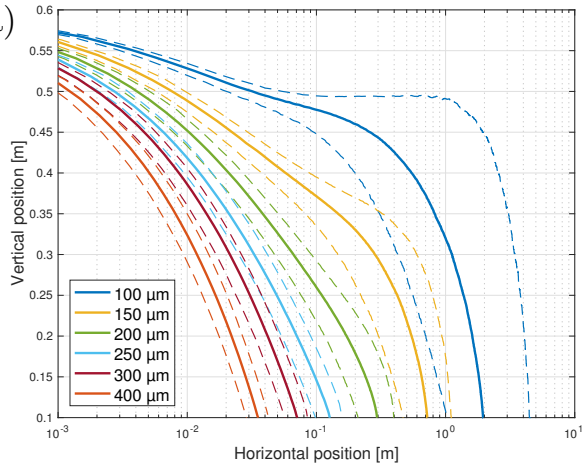

b)

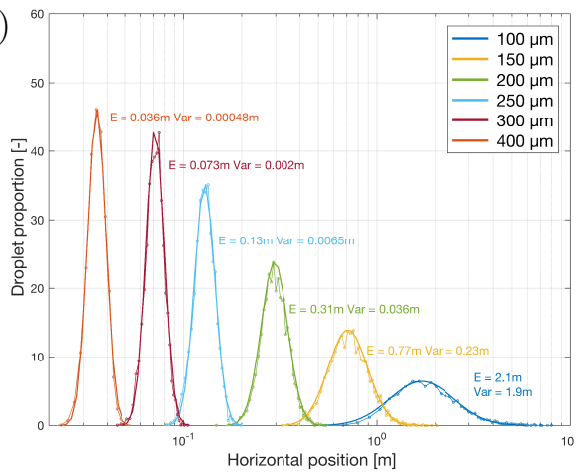

Fig. 5: a) $5^{\text {th }}$ percentile, median and $95^{\text {th }}$ percentile trajectories for 6 different droplet sizes under standard conditions. b) Deposition pattern of 15000 droplets with the same size under standard conditions. The line with the bullets represents the simulated data and the full lines represents the log-normal fit. The log-normal distribution arithmetic mean and the arithmetic variance are displayed above each curves. Details on these parameters are available in the Appendix B.

than $200 \mu \mathrm{m}$ reached the canopy within $1 \mathrm{~m}$ from the release position with a dispersion shorter than $0.1 \mathrm{~m}$.

The $95^{t h}$ percentile curve for the $100 \mu m$ droplet features a plateau between $0.1 \mathrm{~m}$ and $1 \mathrm{~m}$. This plateau arises from a succession of random velocity fluctuations directed upwards. At a wind speed of $2 \mathrm{~m} \mathrm{~s}^{-1}$ at $2 \mathrm{~m}$ height, the vertical velocity fluctuations are equal to $u_{z}^{\prime}=0.284 \epsilon$ with $\epsilon$ a random standard Gaussian value which is in the same range than the settling velocity of droplet of $100 \mu m$ (i.e. $0.29 \mathrm{~m} \mathrm{~s}^{-1}$ ). Computations (not displayed here for brevity) showed that with a higher wind speeds, the plateau forms a bell shape due to the increase in the strength of the vertical velocity fluctuations.

The simulated relative deposition patterns over distance is shown in Figure5b by dashed with bullets. The full line represents the log-normal fit on the simulated data. The fitted and simulated data are in good agreement. The next subsection assess the effect of the wind speed and the release parameters on the arithmetic mean of the log-normal distribution. The value of the arithmetic mean has been retrieved with a least square fitting of the log-normal parameters on the numerical data using Matlab (MATLAB 9.0, The MathWorks Inc., Nat- 

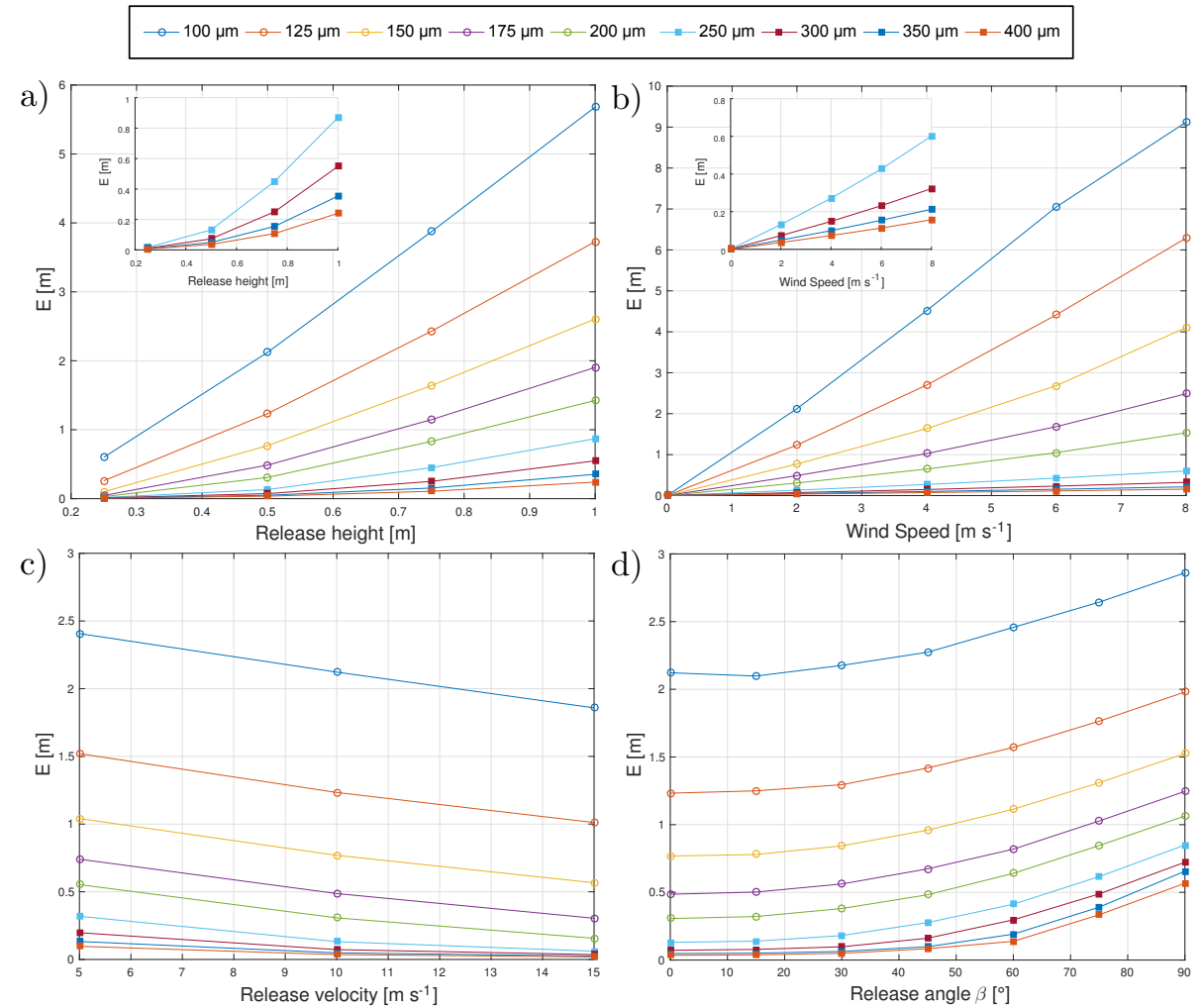

Fig. 6: Effect of the release height, wind speed, release velocity and release angle on the average of the log-normal fit arithmetic mean $E$.

ick, MA, USA). More details about the log-normal distribution and the reduced parameters are furnished in the Appendix B.

\subsubsection{Average droplet transport}

The results of the arithmetic mean $E[\mathrm{~m}]$ with respect to variation of the ejection height, ejection angle, wind speed and ejection velocity are presented in Fig 6. The horizontal distance travelled by a droplet was correlated with droplet ToF and wind speed. ToF decreased with decreasing release velocity and increasing droplet settling velocity. The release height increased the average displacement, mainly for droplet smaller than $250 \mu \mathrm{m}$. For fine droplets, the release height was roughly proportional to the ToF since the droplets quickly 
reached their settling velocities, leading to a linear relationship between travelled distance and release height. For droplets coarser than $200 \mu m$, the latter relationship was not linear because larger droplets adecelerate during their fall. The travelled distance linearly increased with increasing wind speed. Finer droplets were more sensitive to wind speed, resulting in steeper slopes in the graph of Fig 6 b. Increase in the release velocity slightly decreased the traveled distance for the finer droplets $\left(-20 \%\right.$ for $\left.100 \mu m 5-15 \mathrm{~m} \mathrm{~s}^{-1}\right)$ whilst the decrease was substantial for coarse droplets (- $80 \%$ for $400 \mu m 5-15 \mathrm{~m} \mathrm{~s}^{-1}$ ) which relates to droplet inertia. The effect of the release angle $\beta$ is shown in Fig 6 d. For each angle, the average displacement without wind was subtracted to consider the effect of these angles. The increase of $\beta$ leads to a decrease in initial vertical velocity and an increase of the initial horizontal velocity, increasing the averaged travelled distance. Droplets with diameter $\geq 200 \mu m$ had an average horizontal displacement shorter than $0.5 \mathrm{~m}$ for release angle $\leq 60^{\circ}$.

\subsubsection{Droplet transport of $95^{\text {th }}$ percentile}

$X_{95}$ represents the downwind distance by which $95 \%$ of the spray volume has reached the ground. It corresponds to the final position of the $95^{\text {th }}$ percentile trajectories shown in Fig[5]. This parameter was responsive to the average transport of the droplet spray and deposition dispersion. The effect of the main parameters on the $X_{95}$ is shown in Fig.7. The increase of release height was linear with increasing $X_{95}$, similarly to Fig 6 a. However, the decrease of the slope with increasing droplet size was stronger than for the average displacement since the increase of height also enhanced the deposition variability. The increase of wind speed generated a quadratic increase of the $X_{95}$. This can be explained by an increase in the random wind fluctuations which in turn enhanced the variability of the droplet trajectories. Therefore, the log-normal curves representing the volume distribution over distance were strongly flattened.At windspeeds of $8 \mathrm{~m} \mathrm{~s}^{-1}$, more than $5 \%$ of the droplets of $100 \mu \mathrm{m}$ travelled further than $100 \mathrm{~m}$. This distance dropped below $1 \mathrm{~m}$ for droplets with diameter $\geq 250 \mu \mathrm{m}$. The increase of the release velocity led to a moderate decrease of $X_{95}$. Thus, acting 

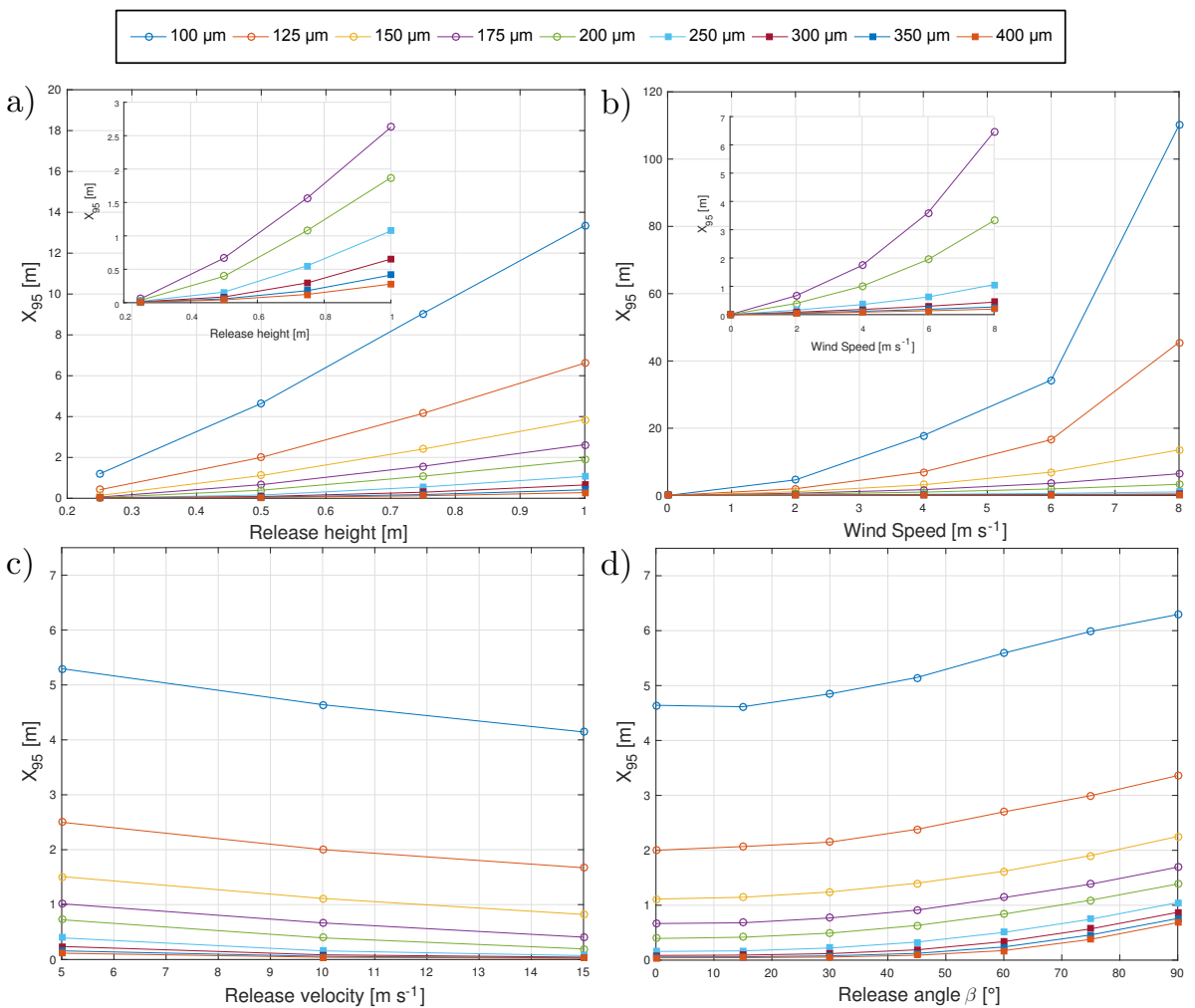

Fig. 7: Effect of the release height, wind speed, release velocity and release angle on the distance above which $95 \%$ of the droplets have reach the top canopy level $X_{95}$. 

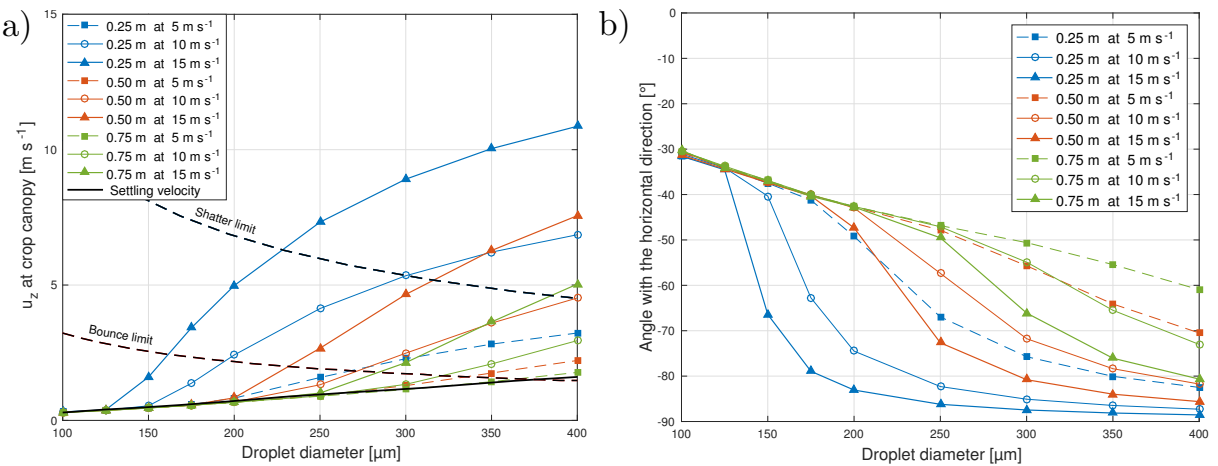

Fig. 8: a) Average impact velocity in respect to the droplet diameter for three release heights and three release velocities. The dashed line shows the velocity above which a droplet would shatter or bounce while impact a wheat leaf using the adhesion model described in section 2.2 b) Average droplet trajectory angle at the crop top canopy level with the horizontal direction. The other simulation parameters were set at standard values (cf Table 2 .

solely on the release velocity does not significantly affect drift. The increase of $\beta$ led to an increase of $X_{95}$, especially for coarser droplets at release angles from $60^{\circ}$ to $90^{\circ}$. At an angle of $60^{\circ}$, less than $5 \%$ of the droplets with diameter $\geq$ $200 \mu \mathrm{m}$ were airborne further than $1 \mathrm{~m}$. $X_{95}$ was strongly influence by droplet size due to the higher deposition variability and higher average displacement for finer droplets. This means that droplets diameter $\leq 150 \mu \mathrm{m}$ should be minimised within the spray since a significant proportion will travel several metres. E and $X_{95}$ were close to each other for droplets with diameter $\geq 250 \mu \mathrm{m}$ showing a low dispersion of droplet trajectories. This low dispersion can be explained by their shorter ToF relatively to finer droplets.

\subsubsection{Droplet velocity at top canopy level}

Figure 8 a shows the average droplet vertical velocity at crop height for three release heights and three release velocities. The coarser the droplet, the shorter is the travelled distance and the faster it may impact on the target. The black line shows experimental measurements of settling velocities (Gunn \& Kinzer 1949). At a release height of $0.5 \mathrm{~m}$, droplets smaller with diameter $\leq 200 \mu \mathrm{m}$ reached their settling velocity. At $350 \mu \mathrm{m}$ diameter, the $0.25 \mathrm{~m}$ and $10 \mathrm{~m} \mathrm{~s}^{-1}$ 
line crosses the $0.5 \mathrm{~m}^{15 \mathrm{~m} \mathrm{~s}^{-1}}$ line showing that the increase of release velocity overcomes the increase in flight distance for droplets with higher inertia. The black dashed line shows the thresholds for droplet bounce and shatter on a wheat leaf predicted for water (Dorr et al. 2015). For the whole range of droplet size studied, shatter occurs when the droplets move faster than their settling velocity. For standard simulation conditions (i.e. $0.5 \mathrm{~m}$ and $10 \mathrm{~m} \mathrm{~s}^{-1}$ ) droplets larger than $400 \mu \mathrm{m}$ shattered and droplets between 270 and $400 \mu \mathrm{m}$ bounced. The mitigation of bounce and shatter can be done by increasing the release height or by decreasing the release velocity. Nevertheless, decreasing the release velocity was predicted as being less detrimental for the spray drift as shown in Fig, 6 a,c.

Droplet trajectory at the top canopy affects the potential droplet retention. For graminicide application, vertical trajectories reduce the droplet capture probability by the target (Jensen, 2012, Spillman, 1984). Figure8b shows the average trajectory angles in respect with the horizontal direction under a wind of $2 \mathrm{~ms}^{-1}$ at $2 \mathrm{~m}$ above the crop. The droplet ToF and the droplet size will affect the final horizontal velocity whilst the droplet size, release height and the release velocity will determine the final vertical velocity. The fine and therefore slow droplets reach the canopy more horizontally than the coarse ones. For a release height of $0.5 \mathrm{~m}$, the droplets reached the top of the canopy with roughly the same horizontal velocity as shown in Fig 4 b. Therefore, the difference in angle between droplet size may be mainly related to the vertical velocity component.

\subsubsection{Droplet evaporation}

The effect of the relative humidity $H r$, wind speed and droplet size on the evaporated fraction is shown in Fig.9. The evaporated fraction was computed by subtracting the volume of liquid reaching the top canopy from the initial volume released. Evaporation mainly affects droplets with diameter $\leq 150 \mu \mathrm{m}$. Droplets with diameter $\geq 250 \mu m$ had moderate evaporation, i.e. $\leq 3 \%$ for the worst scenario. Therefore, for droplet $\geq 250 \mu \mathrm{m}$ diameter, the evaporation may 

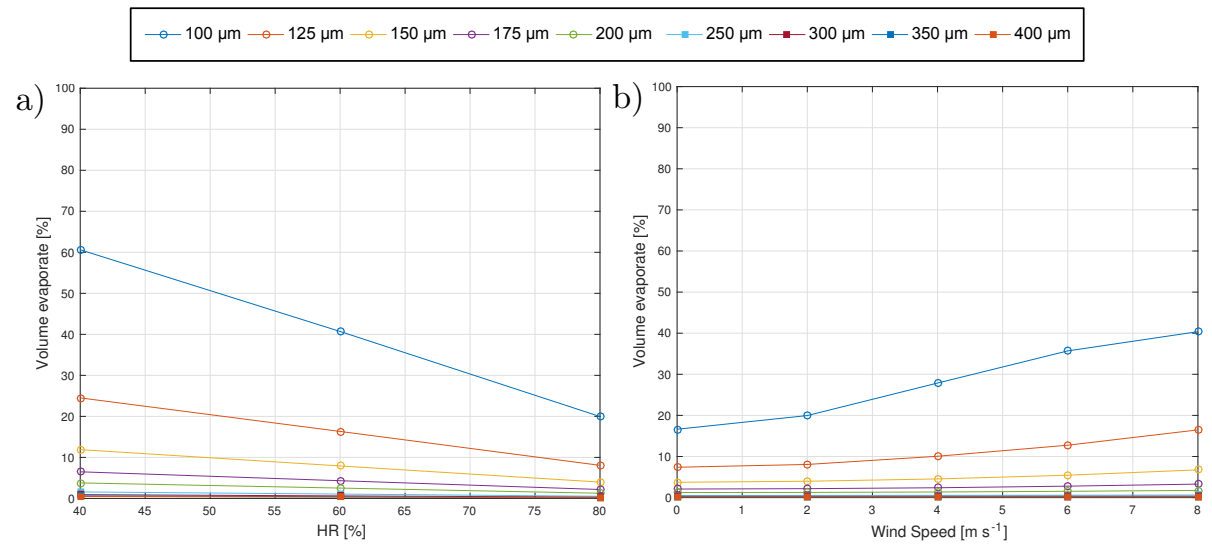

Fig. 9: Evolution of the relative volume evaporate in respect to the relative humidity and the wind speed.

not be a concern. The evaporation model does not take into account the small increase in vapour pressure in the surrounding air due to the droplet evaporation. Therefore the evaporation rate observed in real conditions could be lower.

\subsection{Polydisperse sprays}

\subsubsection{Deposition}

Figure 10 a shows the volume of spray airborne with respect to the distance from the nozzle for twelve simulations with different $D v_{50}$ and $R S F$. As expected, increasing $D v_{50}$ reduces the volume of airborne spray. Increasing $D v_{50}$ from $150 \mu \mathrm{m}$ to $350 \mu \mathrm{m}$ reduces the airborne spray at $2 \mathrm{~m}$ from $20 \%$ to $2 \%$. Comparison of sprays with the same $D v_{50}$ shows that lower the $R S F$ can reduce drift. For a $D v_{50}$ of $150 \mu m$, decreasing of $R S F$ from 1 to 0.6 produces a reduction from $20 \%$ to $12 \%$ of the airborne spray at $2 \mathrm{~m}$. Table 3 summarises the airborne spray reduction at several distances induced by reducing the $R S F$ from 1.0 to 0.6 computed as: $100 \frac{\text { Drift }_{0.6}}{\text { Drift }_{1.0}}$. The drift reduction produced by the $R S F$ reduction increased with the $D v_{50}$ because the coarser the spray, the greater the relative reduction of the fine droplets. For the spray with a $D v_{50}$ of $250 \mu \mathrm{m}$, drift reduction was around $80 \%$ which corresponds to a three star rating in the LERAP scheme Butler Ellis, Alanis, Lane, Tuck, Nuyttens \& 
Table 3: Airborne spray reduction [\%] induced by a $R S F$ reduction from 1.0 to 0.6. The airborne spray reduction is given for each $D v_{50}$ at 5 distances from the release point.

\begin{tabular}{|c|c|c|c|c|c|c|}
\hline & & \multicolumn{5}{|c|}{ Distance $[\mathrm{m}]$} \\
\hline & & 2 & 4 & 6 & 8 & 10 \\
\hline \multirow{6}{*}{ 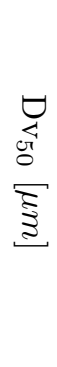 } & 150 & 43.4 & 56.0 & 55.7 & 49.2 & 42.9 \\
\hline & 200 & 67.3 & 76.1 & 76.0 & 73.5 & 70.8 \\
\hline & 225 & 74.2 & 81.3 & 81.2 & 79.9 & 77.2 \\
\hline & 250 & 80.3 & 85.4 & 85.4 & 83.5 & 80.4 \\
\hline & 300 & 87.0 & 90.6 & 90.0 & 88.3 & 87.0 \\
\hline & 350 & 90.6 & 93.1 & 93.4 & 93.1 & 92.7 \\
\hline
\end{tabular}

van de Zande, 2017). For each $D v_{50}$ the drift reduction appeared to be roughly constant over distance.

\subsubsection{Retention}

Figure 11 shows the relative volume of each droplet impact for the twelve simulated sprays on a wheat leaf. For a given $R S F$, the increase of $D v_{50}$ leads to a monotonic decrease of adhesion and the emergence of bounce and shatter due to a progressive increase of larger droplet proportion. Reduction of $R S F$ enhanced one outcome according to the $D v_{50}$, for $D v_{50} \leq 250 \mu m$ there was an increase of the adhesion whilst bounce increased for $D v_{50} \geq 300 \mu \mathrm{m}$. For standard conditions, the diameter threshold between adhesion and bounce is around $270 \mu \mathrm{m}$ as shown in Fig 8 a. Therefore, a $R S F$ reduction may be detrimental if the $D v_{50}$ is not in the adequate range as has already been noted in previous theoretical work (Massinon, De Cock, Ouled Taleb Salah \& Lebeau, 2016).

\section{Discussion}

The study of the droplet transport dynamic has shown that the size of a droplet affects its trajectory. The finer the droplet longer its time in the air making it more sensitive to evaporation and drift. The droplet ToF can be 


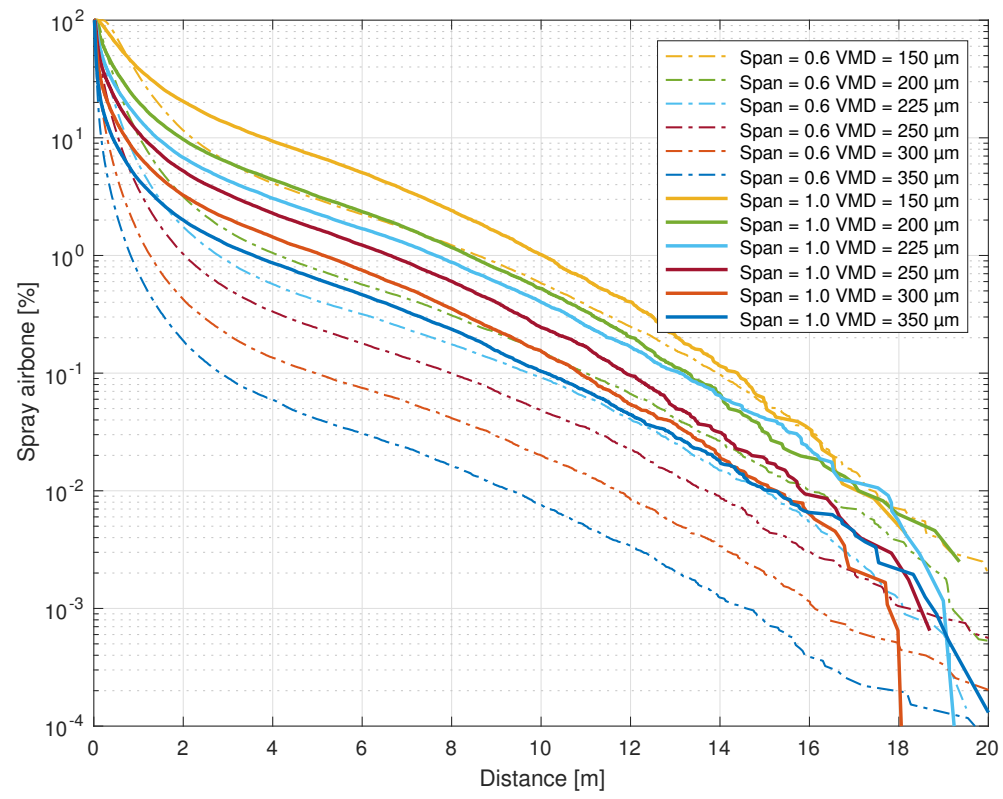

Fig. 10: Volume of airborne spray in respect with the distance. Twelve sprays were simulated with different $D v_{50}$ and $R S F$ values. The outcomes have been determined at the top canopy level using the models described in the section 2.2 for a release height of $0.5 \mathrm{~m}$ and a release speed of $10 \mathrm{~ms}^{-1}$. 


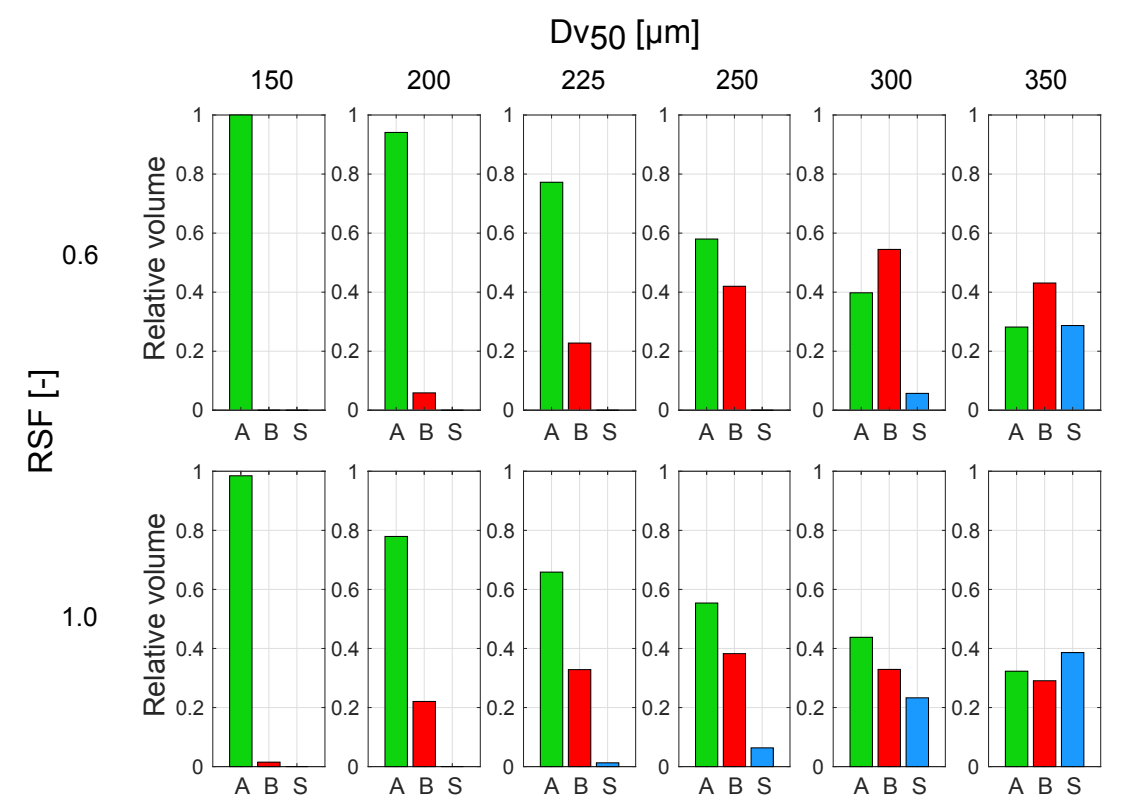

Fig. 11: Droplet impact outcome predictions at top canopy level expressed in relative volume. $A, B$ and $S$ correspond to adhesion, bounce and shatter respectively.

shortened by decreasing the release height or by increasing the release velocity. Release angle and release velocity have moderate effects on fine droplets. However for coarse droplets, increasing the release velocity increases the droplet velocity at the canopy and thus its outcome during impaction. The change of the release angle from vertical to horizontal direction leads to an increase in the travelled distance arising from both the initial horizontal velocity and the increase in ToF. An optimum value may be around $60^{\circ}$. The wind speed is enhances the average droplet travelled distance linearly and the maximum distance quadratically. However, with droplets of $250 \mu \mathrm{m}$, and $8 \mathrm{~m} \mathrm{~s}^{-1}$ wind speed $95 \%$ of the spray reached canopy top level below $1 \mathrm{~m}$ from the release point. The shatter threshold on a wheat leaf was reached by droplets larger than $400 \mu \mathrm{m}$ when the release height is at $0.5 \mathrm{~m}$ and the release speed at $10 \mathrm{~m} \mathrm{~s}^{-1}$. With tthese initial conditions, bounce occurs for droplet between 270 and $400 \mu \mathrm{m}$. Therefore, droplets with a diameter from 200 to $270 \mu m$ have a low drift potential and may not shatter or bounce on a wheat leaf. 
For a polydisperse sprays, the overall behaviour can be seen as the combination of drop size distribution and the properties of each droplet size. Drift and the volume of droplet adhesion decrease with increasing $D v_{50}$. Narrowing the $R S F$ of the spray may solve this problem. A spray with a $D v_{50}$ of $225 \mu \mathrm{m}$ and a $R S F$ of 0.6 released at $0.5 \mathrm{~m}$ at $10 \mathrm{~m} \mathrm{~s}^{-1}$ above the crop produces low drift with moderate kinetic energy at the crop canopy level. Using a Weibull distribution, this spray would have a $D v_{10}$ of $152 \mu \mathrm{m}, D v_{90}$ of $288 \mu \mathrm{m}$ with $1.4 \%$ of the droplet volume $\leq 100 \mu \mathrm{m}$ diameter and $9.5 \% \leq 150 \mu \mathrm{m}$ diameter. The narrowing of the spray drift may be detrimental when the $D v_{50}$ is too small or too large which would enhanced drift or decreases retention.

\section{Conclusion}

A combined Lagrangian droplet transport and retention models has been presented. The deposition over distance had a log-normal distribution with a dispersion and average distance larger for finer droplets. The results of numerical simulations showed that droplets with diameters ranging between $200 \mu \mathrm{m}$ and $250 \mu \mathrm{m}$ offered high control of deposition by combining a low drift potential and moderate kinetic energy at the top of the canopy. The reduction of the $R S F$ from 1.0 to 0.6 is an effective way to mitigate deposition and retention losses. A fourfold reduction of the drift volume at a distance of $2 \mathrm{~m}$ from the nozzle was observed for a spray with a $D v_{50}=225 \mu \mathrm{m}$ when the $R S F$ was reduced from 1.0 to 0.6. Under this scenario, an increase in the volumetric proportion of adhering droplets on a wheat leaf from 63 to $78 \%$ was shown. Therefore, strategies to control the droplet size distribution in terms of $D v_{50}$ and $R S F$ may offer promising solutions for reducing adverse impacts on environment of spray applications.

Further work should be carried out on the experimental assessment of the performance of such sprays in term of drift reduction and retention on target. Sprays with a $R S F$ around 0.6 and a $D v_{50}$ of $225 \mu \mathrm{m}$ appear to feasible using rotary atomisers (Qi et al., 2008). 


\section{Acknowledgments}

This work was supported by the Fonds De La Recherche Scientifique - FNRS, under the FRIA grant $n^{\circ} 97364$.

\section{References}

Al Heidary, M., Douzals, J. P., Sinfort, C., \& Vallet, A. (2014). Influence of spray characteristics on potential spray drift of field crop sprayers: A literature review. Crop Protection, 63, 120-130.

Attané, P., Girard, F., \& Morin, V. (2007). An energy balance approach of the dynamics of drop impact on a solid surface. Physics of Fluids, 19, 012101.

Babinsky, E., \& Sojka, P. E. (2002). Modeling drop size distributions. Progress in Energy and Combustion Science, 28, 303-329.

Baetens, K., Ho, Q. T., Nuyttens, D., De Schampheleire, M., Melese Endalew, A., Hertog, M. L. A. T. M., Nicolai, B., Ramon, H., \& Verboven, P. (2009). A validated 2-D diffusion-advection model for prediction of drift from ground boom sprayers. Atmospheric Environment, 43, 1674-1682.

Baetens, K., Nuyttens, D., Verboven, P., De Schampheleire, M., Nicolai, B., \& Ramon, H. (2007). Predicting drift from field spraying by means of a 3D computational fluid dynamics model. Computers and Electronics in Agriculture, $56,161-173$.

Barati, R., Neyshabouri, S. A. A. S., \& Ahmadi, G. (2014). Development of empirical models with high accuracy for estimation of drag coefficient of flow around a smooth sphere: An evolutionary approach. Powder Technology, 257, 11-19.

Butler Ellis, M. C., Alanis, R., Lane, A. G., Tuck, C. R., Nuyttens, D., \& van de Zande, J. (2017). Wind tunnel measurements and model predictions for estimating spray drift reduction under field conditions. Biosystems Engineering, 154, 25-34. 
Butler Ellis, M. C., \& Miller, P. C. H. (2010). The Silsoe spray drift model: A model of spray drift for the assessment of non-target exposures to pesticides. Biosystems Engineering, 107, 169-177.

De Cock, N., Massinon, M., Nuyttens, D., Dekeyser, D., \& Lebeau, F. (2016). Measurements of reference ISO nozzles by high-speed imaging. Crop Protection, 89, 105-115.

Dorr, G. J., Wang, S., Mayo, L. C., McCue, S. W., Forster, W. A., Hanan, J., \& He, X. (2015). Impaction of spray droplets on leaves: influence of formulation and leaf character on shatter, bounce and adhesion. Experiments in Fluids, $56,143$.

Forster, W. A., Mercer, G. N., \& Schou, W. C. (2010). Process-driven models for spray droplet shatter, adhesion or bounce. In Proceedings of the 9th International Symposium on Adjuvants for Agrochemicals (p. 20). volume 16.

Guella, S., Alexandrova, S., \& Saboni, A. (2008). Evaporation d'une gouttelette en chute libre dans l'air. International Journal of Thermal Sciences, 47, 886898.

Gunn, R., \& Kinzer, G. D. (1949). The terminal velocity of fall for water droplets in stagnant air. Journal of Meteorology, 6, 243-248.

Hilz, E., \& Vermeer, A. W. P. (2013). Spray drift review: The extent to which a formulation can contribute to spray drift reduction. Crop Protection, 44 , $75-83$.

Holterman, H. J., Van De Zande, J. C., Porskamp, H., \& Huijsmans, J. (1997). Modelling spray drift from boom sprayers. Computers and Electronics in Agriculture, 19, 1-22.

Jensen, P. K. (2012). Increasing efficacy of graminicides with a forward angled spray. Crop Protection, 32, 17-23. 
Josserand, C., \& Thoroddsen, S. T. (2016). Drop impact on a solid surface. Annual Review of Fluid Mechanics, 48, 365-391.

Kok, J. F., \& Renno, N. O. (2009). A comprehensive numerical model of steady state saltation (COMSALT). Journal of Geophysical Research: Atmospheres, 114 .

Langmuir, I., \& Blodgett, K. B. (1949). A mathematical investigation of water droplet trajectories. Technical report No. RL225. General Electric Schenectady N.Y.

Lebeau, F. (2004). Modelling the dynamic distribution of spray deposits. Biosystems Engineering, 89, 255-265.

Lebeau, F., Verstraete, A., Stainier, C., \& Destain, M. F. (2011). RTDrift: A real time model for estimating spray drift from ground applications. Computers and Electronics in Agriculture, 77, 161-174.

Mao, T., Kuhn, D., \& Tran, H. (1997). Spread and rebound of liquid droplets upon impact on flat surfaces. AIChE Journal, 43, 2169-2179.

Massinon, M., De Cock, N., Forster, W. A., Nairn, J. J., McCue, S. W., Zabkiewicz, J. A., \& Lebeau, F. (2017). Spray droplet impaction outcomes for different plant species and spray formulations. Crop Protection, 99, 65-75.

Massinon, M., De Cock, N., Ouled Taleb Salah, S., \& Lebeau, F. (2016). Reduced span spray-part 1: Retention. Aspect of Applied Biology, International Advances in Pesticide Application, 132, 323-330.

Massinon, M., Dumont, B., De Cock, N., Salah, S. O. T., \& Lebeau, F. (2015). Study of retention variability on an early growth stage herbaceous plant using a 3D virtual spraying model. Crop Protection, 78, 63-71.

Mokeba, M. L., Salt, D. W., Lee, B. E., \& Ford, M. G. (1997). Simulating the dynamics of spray droplets in the atmosphere using ballistic and random-walk 
models combined. Journal of Wind Engineering and Industrial Aerodynamics, 67, 923-933.

Mundo, C. H. R., Sommerfeld, M., \& Tropea, C. (1995). Droplet-wall collisions: experimental studies of the deformation and breakup process. International Journal of Multiphase Flow, 21, 151-173.

Nuyttens, D., Baetens, K., De Schampheleire, M., \& Sonck, B. (2007a). Effect of nozzle type, size and pressure on spray droplet characteristics. Biosystems Engineering, 97, 333-345.

Nuyttens, D., De Schampheleire, M., Baetens, K., \& Sonck, B. (2007b). The influence of operator-controlled variables on spray drift from field crop sprayers. Transactions of the ASABE, 50, 1129-1140.

Panofsky, H. A., Tennekes, H., Lenschow, D. H., \& Wyngaard, J. C. (1977). The characteristics of turbulent velocity components in the surface layer under convective conditions. Boundary-Layer Meteorology, 11, 355-361.

Qi, L., Miller, P. C. H., \& Fu, Z. (2008). The classification of the drift risk of sprays produced by spinning discs based on wind tunnel measurements. Biosystems Engineering, 100, 38-43.

Raupach, M. R., Briggs, P. R., Ford, P. W., Leys, J. F., Muschal, M., Cooper, B., \& Edge, V. (2001). Endosulfan transport. Journal of Environmental Quality, 30, 714-728.

Reichenberger, S., Bach, M., Skitschak, A., \& Frede, H.-G. (2007). Mitigation strategies to reduce pesticide inputs into ground-and surface water and their effectiveness; a review. Science of the Total Environment, 384, 1-35.

Rosin, P., \& Rammler, E. (1933). The laws governing the fineness of powdered coal. Journal of the Institute of Fuel, 7, 29-36.

Saboni, A., Alexandrova, S., \& Gourdon, C. (2004). Détermination de la trainée engendrée par une sphère fluide en translation. Chemical Engineering Journal, 98, 175-182. 
Sawford, B. L., \& Guest, F. M. (1991). Lagrangian statistical simulation of the turbulent motion of heavy particles. Boundary-Layer Meteorology, 54, $147-166$.

Spillman, J. J. (1984). Spray impaction, retention and adhesion: an introduction to basic characteristics. Pest Management Science, 15, 97-106.

Stainier, C., Destain, M. F., Schiffers, B., \& Lebeau, F. (2006). Droplet size spectra and drift effect of two phenmedipham formulations and four adjuvants mixtures. Crop Protection, 25, 1238-1243.

Taylor, W. A., Womac, A. R., Miller, P. C. H., \& Taylor, B. P. (2004). An attempt to relate drop size to drift risk. In Proceedings of the International Conference on Pesticide Application for Drift Management (pp. 210-223).

Teske, M. E., Bird, S. L., Esterly, D. M., Curbishley, T. B., Ray, S. L., \& Perry, S. G. (2002). Agdrift $\AA$ : A model for estimating near-field spray drift from aerial applications. Environmental Toxicology and Chemistry, 21, 659-671.

Walklate, P. J. (1987). A random-walk model for dispersion of heavy particles in turbulent air flow. Boundary-Layer Meteorology, 39, 175-190.

Weiner, K. L., \& Parkin, C. S. (1993). The use of computational fluid dynamic code for modelling spray from a mistblower. Journal of Agricultural Engineering Research, 55, 313-324.

Wilson, J. D., \& Sawford, B. L. (1996). Review of Lagrangian stochastic models for trajectories in the turbulent atmosphere. Boundary-layer Meteorology, 78, 191-210.

Yarin, A. L. (2006). Drop impact dynamics: splashing, spreading, receding, bouncing. Annual Review of Fluid Mechanics, 38, 159-192.

Zabkiewicz, J. A. (2007). Spray formulation efficacy-holistic and futuristic perspectives. Crop Protection, 26, 312-319. 


\section{Appendix A}

The mass flux is given by:

$$
\dot{m}=A \frac{S h_{g} D_{g}}{d} \rho_{g}\left(Y_{v, s}-Y_{s, \infty}\right)
$$

with $A$ the droplet area $\left[\mathrm{m}^{2}\right], d$ the droplet diameter, $S h_{g}$ the gaseous Sherwood number [-], $D_{g}$ the molecular diffusion $\left[\mathrm{m} \mathrm{s}^{-2}\right], Y_{v, s}$ and $Y_{v, \infty}$ are the vapor mass fractions at the droplet interface and far from the droplet respectively [-]. For a diameters less than $5 \mathrm{~mm}, S h_{g}$ can be computed as:

$$
S h_{g}=1.61+0.718 R e^{0.5} S c_{g}^{0.33}
$$

with $S c_{g}$ the Schmidt number for the gaseous phase [-] expressed by: $S c_{g}=$ $\frac{\nu}{D_{g}}$

The molar fraction at the droplet surface $Y_{v, s}$ is computed as:

$$
Y_{v, s}=y_{l}^{v} \frac{M_{l}}{M_{t}}
$$

with $y_{l}^{v}=\frac{P_{s a t}}{P_{t o t}}$ and $M_{t}=y_{l}^{v} M_{l}+\left(1-y_{l}^{v}\right) M_{g} . M_{l}$ and $M_{g}$ are the molar mass of the liquid and the gaseous phase respectively $\left[\mathrm{g} \mathrm{mol}^{-1}\right]$. Therefore, at atmospheric pressure the vapour mass fraction at the droplet interface neighbourhood, $Y_{v, s}$, reads:

$$
Y_{v, s}=\frac{P_{s a t}}{P_{s a t}+\left(P_{t o t}-P_{s a t}\right) \frac{M_{g}}{M_{l}}}
$$

The vapour pressure in the far field is computed using the relative humidity $H r$ :

$$
Y_{\text {inf }}=H r \frac{P_{\text {sat }}}{H r P_{\text {sat }}+\left(P_{\text {tot }}-H r P_{\text {sat }}\right)\left(\frac{M_{g}}{M_{l}}\right)}
$$

The droplet exchanges heat with the air by convection. The heat flux between the droplet surface and the surrounding air $\dot{Q}_{d}\left[\mathrm{~J} \mathrm{~s}^{-1}\right]$ reads:

$$
\dot{Q}_{d}=S_{l} \frac{N u_{g} \lambda_{g}}{d}\left(T_{\mathrm{inf}}-T_{l}\right)
$$




\section{Appendix B}

The cumulative distribution function (CDF) of a log-normal distribution is defined as:

$$
C D F=\frac{1}{x \sigma_{n} \sqrt{2 \pi}} e^{-\frac{\left(l n(x)-\mu_{n}\right)^{2}}{2 \sigma_{n}^{2}}}
$$


556 with $\sigma_{n}$ and $\mu_{n}$ the two log-normal distribution parameters. From these param-

557 eters reduced variables can be extracted: the arithmetic mean $\mathrm{E}=e^{\mu_{n}+0.5 \sigma_{n}^{2}}$

558 and the arithmetic variance $\operatorname{Var}=e^{2 \mu_{n}+2 \sigma_{n}^{2}}\left(e^{\sigma_{n}^{2}}-1\right)$. 